\title{
The impact of a lung cancer computed tomography screening result on smoking abstinence
}

\author{
C.M. van der Aalst*,\#, R.J. van Klaveren\#, K.A.M. van den Bergh*, \\ M.C. Willemsen ${ }^{\uparrow,+}$ and H.J. de Koning*
}

ABSTRACT: Receiving a lung cancer computed tomography screening result might be a teachable moment for smoking cessation, but it might also unintentionally reassure smokers to continue smoking. The objective of the present study was to investigate whether test results were associated with smoking abstinence in the Dutch-Belgian Randomised Controlled Lung Cancer Screening Trial (NELSON trial).

Two random samples of male smokers who had received either only negative test results $(n=550)$ or one or more indeterminate test result $(n=440)$ were sent a questionnaire 2 yrs after randomisation.

Smokers with an indeterminate result reported more quit attempts $(p=0.02)$, but the prolonged abstinence rate in smokers receiving a negative test (46 (8.9\%) out of 519 subjects) was comparable with the abstinence rate in smokers with one or more indeterminate results (48 (11.5\%) out of 419 subjects) $(p=0.19)$. A statistically insignificant increase was found after one or more indeterminate test result (10.9 and $15.0 \%$, respectively) compared with receiving only negative test results $(8.9 \%)(p=0.26)$.

In conclusion, the outcome of the screening test had no impact on future smoking abstinence in male smokers, although all results suggest more favourable implications after one or more followup recommendations. Screening test outcomes could be used as a teachable moment for smoking cessation.

KEYWORDS: Lung cancer screening, prevention and control, smoking behaviour

ung cancer, the leading cause of cancer deaths, is often diagnosed at an advanced stage and occurs increasingly amongst former smokers [1], which underlines the need for preventive measures. Several randomised screening trials are evaluating the (cost-)effectiveness of lung cancer computed tomography (CT) screening in reducing lung cancer mortality $[2,3]$.

Even though the population eligible for lung cancer screening usually has a long-term smoking history [4], significant health benefits might be achieved by smoking cessation, even in this highrisk population [5, 6]. However, resistance to quitting smoking is high in this population [7] and this group of smokers is often under-represented in smoking cessation interventions [8].

Healthcare events, such as receiving an abnormal test result or an unfavourable medical diagnosis, might be teachable moments that increase the motivation to quit smoking [8-11]. So far, there is no strong evidence that people at high risk for lung cancer who receive an abnormal lung cancer screening test result will be more prone to quit smoking than those with a normal test result or vice versa. A single baseline CT test result appeared to have no impact on smoking abstinence rates or change in smoking behaviour in studies by ANDERSON et al. [12], Cox et al. [13], Ostroff et al. [14] and TAYLOR et al. [15]. In contrast, the number of multiple abnormal lung cancer screening test results was positively associated with smoking cessation in the Mayo Clinic trial after 3 yrs of follow-up [16]. ASHRAF et al. [17] and STYN et al. [18] also found a higher quit rate after a positive test result or referral to a physician, and OSTROFF et al. [14] concluded that participation in lung cancer screening programmes had a major impact on smoking behavioural changes, and that participants were convinced of the health benefits of smoking cessation.

In most lung cancer CT screening trials, the number of subjects with a positive test result that

\section{AFFILIATIONS}

*Dept of Public Health, and

\#Dept of Pulmonology, Erasmus MC, University Medical Centre Rotterdam, Rotterdam,

"STIVORO - Dutch Expertise Centre on Tobacco Control, The Hague, and +School for Public Health and Primary Care (Caphri), Dept of Health Promotion, Faculty of Health, Medicine and Life Sciences, Maastricht University, Maastricht, The Netherlands.

CORRESPONDENCE

C.M. van der Aalst

Dept of Public Health/Pulmonology,

Erasmus MC

University Medical Centre Rotterdam PO Box 2040

3000 CA Rotterdam

The Netherlands

E-mail: c.vanderaalst@

erasmusmc.nl

Received:

Oct 272010

Accepted after revision: Nov 092010

First published online:

Dec 092010 
require referral for work-up and diagnosis is high [13-16]. In the Dutch-Belgian Randomised Controlled Lung Cancer Screening Trial (NELSON trial), we used a novel strategy for the management of lung nodules [3]. After an indeterminate test result, a recall CT scan to assess nodule growth was introduced. This new approach led to a substantial reduction in the number of positive tests and, therefore, fewer referrals to the pulmonologist for work-up, without losing significant diagnostic performance [3]. This novel strategy might also have a different effect on smoking behaviour changes compared with the current nodule management algorithms. Therefore, our objective in the present study was to investigate whether the CT screening test result (negative versus indeterminate) was related to future smoking abstinence amongst 50-75-yr-old male smokers who participated in the NELSON trial. In addition, we investigated whether the number of indeterminate screening test results was associated with an increased quit rate and aimed to identify baseline characteristics associated with prolonged smoking abstinence after 2 yrs of follow-up.

\section{MATERIALS AND METHODS}

\section{Study population}

NELSON trial

The recruitment and selection procedure of the NELSON study participants has been described previously [19]. In summary, based on population registries, 15,822 eligible people aged 50-75 yrs, who signed the informed consent, were randomised to the screen or control arm (1:1) in two recruitment rounds. Participants eligible for the NELSON trial were current or former smokers who had smoked $>15$ cigarettes a day for $>25$ yrs or $>10$ cigarettes a day for $>30$ yrs. Former smokers should have quit smoking for $\leqslant 10$ yrs.

Participants in the screening arm underwent screening by lowdose, multidetector CT in years 1, 2 and 4, and no screening was offered to control arm participants. The screening results were either positive, indeterminate or negative according to our nodule management strategy [3]. A positive test result was classified as: 1 ) a solid nodule with a volume $>500 \mathrm{~mm}^{3}$; 2) a solid, pleural-based nodule with a diameter $>10 \mathrm{~mm}$; or 3) partially solid, of which the solid component measured $>500 \mathrm{~mm}^{3}$. An indeterminate test result was classified as: 1) a solid nodule with a volume of $50-500 \mathrm{~mm}^{3}$; 2) a solid, pleural-based nodule with a diameter of $5-10 \mathrm{~mm}$; 3) a partially solid nodule with either a nonsolid component of $>8 \mathrm{~mm}$ mean dimension or a solid component of $50-500 \mathrm{~mm}^{3}$; or 4) a nonsolid nodule with a diameter of $\geqslant 8 \mathrm{~mm}$. In all other cases, the test result was negative. People with a positive screening result were informed about their referral to a pulmonologist by phone, whereas those with either an indeterminate or a negative screening result received only a standard letter explaining that radiologists had or had not found an abnormality. An indeterminate screening result was not classified as a positive screening result, because participants with an indeterminate test result received a letter which was formulated very carefully to avoid possible psychological consequences often reported after a (false-)positive test result. The letter stated: "We have observed a very small abnormality in your lung (5-10 mm long). Such a small abnormality is often detected in many persons and it usually represents a small scar or a minor inflammation. Therefore, at this moment there is no need for any further investigations. However, in order to see whether there has been any change in this abnormality, a new CT scan of the lungs will be made after 3 to 4 months."

Smoking cessation information from STIVORO, the Dutch expert centre on tobacco control, was sent to all current smokers at randomisation. Current smokers received a standard brochure with brief information about how to quit smoking or a questionnaire for tailored smoking cessation information.

The NELSON trial was approved by the Ministry of Health, Welfare and Sports after positive advice of the Dutch Health Council, and by the Medical Ethics Committees of the participating centres.

\section{Effect of a CT screening result on smoking cessation}

The current study was conducted in a random subcohort of two samples of male screening arm participants who were current smokers before randomisation and were randomised in the NELSON trial during the first recruitment round. Participants who had smoked in the 7 days before completing the general questionnaire before randomisation (T0) were classified as current smoker. The random samples included only participants who had received either only negative test results ("test negatives"; $n=550$ ) or at least one indeterminate test result followed by a recommendation for recall CT screening after 3 months ("test indeterminates"; $n=440$ ). Male screening arm participants with a positive test result at follow-up ( $n=53,2.1 \%$ ) or those who went off-study (because of, for example. unavailability, personal reasons, lung cancer or death; $n=163,6.3 \%$ ) were excluded from these samples.

The selected population received a second questionnaire about their actual smoking habits mean \pm SD $2.2 \pm 0.29$ yrs after trial randomisation (T1) and $1.8 \pm 0.35$ yrs after receiving their baseline test result (fig. 1). At follow-up, the test negative group had undergone $2 \pm 0.25$ (only regular-round) CT scans and the test indeterminate group $3 \pm 0.47$ (including regular and recall scans) CT scans.

\section{Measures}

\section{TO: baseline questionnaire}

Participants were asked about their age, sex and level of education. Their smoking history was assessed using questions about: age of smoking onset (8-point scale); average number of cigarettes smoked a day during the years of smoking (10-point scale); and the years of smoking during their lifetime (9-point scale) [19]. The last two variables were recoded into variables with five and four categories, respectively, and into a continuous variable based on the mean value of each category. The intention of quitting smoking was adapted from the Transtheoretical Model and classified according to the stages of change [20,21]. Respondents who had no intention to quit smoking in the near future were defined as immotives, whereas contemplators, pre-contemplators and preparators reported an intention to quit smoking within 6-12 months, $1-6$ months or 1 month, respectively $[20,21]$. Nicotine addiction was estimated using the first question of the Fagerström Test for Nicotine Dependence (FTND), which asked for the time to the first cigarette after waking up $(<5,5-30,30-60$ or $>60 \mathrm{~min})[21,22]$. 


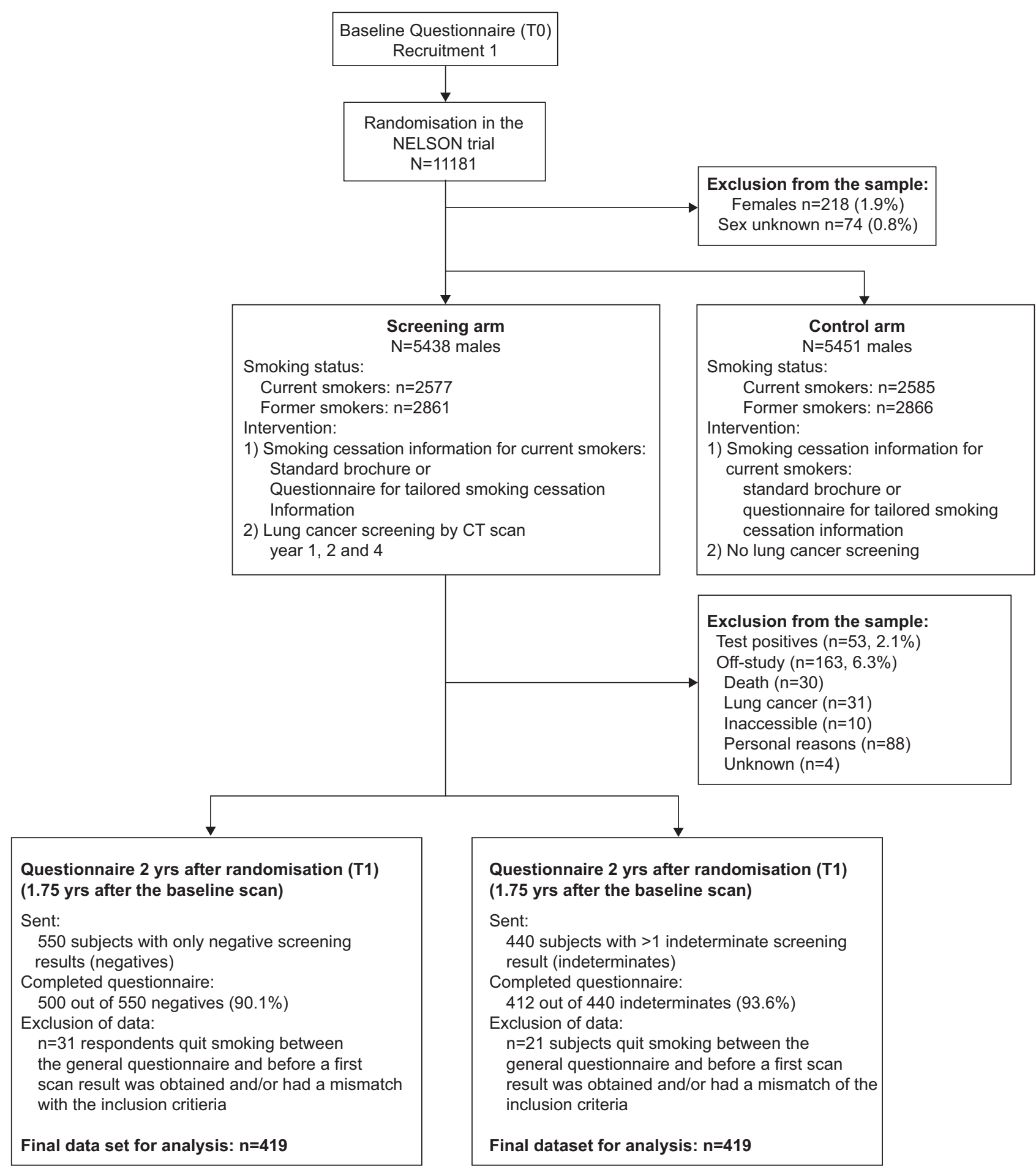

FIGURE 1. Study flowchart. NELSON: Dutch-Belgian Randomised Controlled Lung Cancer Screening Trial; CT: computed tomography.

\section{T1: smoking cessation questionnaire}

The second questionnaire included additional questions about the smoking habits at 2 yrs of follow-up. Current smoking behaviour was measured by asking the participants whether they usually smoked (yes/no), whether they had smoked during the previous $24 \mathrm{~h}$ (yes/no) and/or 7 days (yes/no). Respondents who reported smoking and/or who had smoked in the previous week were defined as current smokers, whereas others were defined as point prevalent abstinent from smoking [23].

To measure smoking abstinence, participants were asked about the number of quit attempts in the last year and whether they were engaged in a quit attempt at that time (yes/no). Former 
smokers were asked about the date of quitting smoking (day/ month/year) and whether they had smoked (not at all, 1-5 cigarettes or $>5$ cigarettes) since the quit date and 2 weeks after the quit date $[23,24]$. Former smokers who had smoked $<5$ cigarettes since the quit date were classified as continued smoking abstinent, while former smokers who had smoked $<5$ cigarettes 2 weeks after their quit date were defined as prolonged smoking abstinent. Those who smoked $>5$ cigarettes were classified as current smokers [23, 24]. The smoking intensity at $\mathrm{T} 1$ was recoded into the categories of the number of cigarettes smoked at T0 (least precise). The transition through these categories was calculated and classified as stable, reduced smoking (lower category) or increased smoking intensity (higher category).

\section{Statistical analysis}

In order to detect an expected quit rate of 5-7\% amongst smokers in the test negative group and 20\% amongst smokers in the test indeterminate group [16, 25] with a power of $100 \%$, the required sample size enrolled in each group was 400 participants.

Continuous variables with a normal distribution are presented as mean $\pm \mathrm{SD}$ and skewed continuous variables are presented as median (interquartile range).

The differences in distributions of baseline characteristics between male smokers of the first recruitment and the subgroups, between the two subgroups and between the respondents and nonrespondents of each subgroup were analysed using Pearson's Chi-squared test for nominal or categorical variables and the Mann-Whitney U-test for continuous variables with a non-normal distribution. The nonrespondents were classified as current smoker and included in the analysis [24].

Differences between former smokers in the negative and indeterminate group were analysed using the Mann-Whitney U-test, unpaired t-test or Chi-squared statistics as appropriate. The effect of the screening result on prolonged smoking abstinence was analysed using both univariate as well as multivariate unadjusted backward stepwise logistic regression analyses using the likelihood ratio test. The variables related to the test results, level of education, motivation to quit smoking and the time to the first cigarette (FTND) were included as categorical variables, while the other variables were included as continuous variables.

Results with a p-value $\leqslant 0.05$ were defined as statistically significant. The power analysis was calculated using the statistical software package $\mathrm{R}$ (The $\mathrm{R}$ Project, Institute for Statistics and Mathematics, Vienna University of Economics and Business, Vienna, Austria). The remaining statistics were performed using the SPSS statistical software package version 15.0 (IBM, Somers, NY, USA).

\section{RESULTS}

\section{Characteristics of the participants}

The response rates to the questionnaires were $90.9 \%$ (500 out of 550 subjects) and $93.6 \%$ (412 out of 440 subjects) for those who received only negative test results and those who received at least one indeterminate test result, respectively (fig. 1). 52 participants were excluded from all further analyses either because they had quit smoking between completion of the general questionnaire before randomisation and their first CT screening test result $(n=31,3.1 \%)$ or because of a mismatch with the inclusion criteria (male current smokers at randomisation) ( $n=21,2.1 \%)$. The response was higher in the negative group compared with the indeterminate group (7.5 versus $4.3 \% ; p=0.04)$, although there was no nonresponse bias $(\mathrm{p}>0.05)$.

The baseline characteristics of the subsamples were representative for the male smokers of the first recruitment of the NELSON trial and the participants of both groups were comparable with regard to baseline characteristics (no statistically significant differences) (table 1 ). Mean \pm SD age was $57.9 \pm 5.0$ and $58.9 \pm 4.9$ yrs in the test negative and indeterminate group, respectively. A total of $49.0 \%$ (249 out of 508) of the test negatives and $53.7 \%$ (220 out of 410 ) of the test indeterminates had a low level of education. Participants with and without a follow-up recommendation had a comparable smoking history between 30-60 pack-yrs (60.7\% (315 out of 519 ) versus $59.6 \%$ (249 out of 418 ), respectively). $70 \%$ (362 out of 519 ) of the test negatives and $62.3 \%$ (261 out of 419$)$ of the test indeterminates started smoking between 15-20 years of age, and $58.6 \%$ of the test negatives and $61.8 \%$ of the test indeterminates reported an intention to quit smoking. A high level of nicotine addiction was reported in $17.9 \%$ (88 out of 492) of the test negatives and $22.8 \%$ (90 out of 395 ) of the test indeterminates $(p=0.04)$, as estimated by subjects smoking their first cigarette within 5 min after waking up.

\section{Screening test results and smoking abstinence}

After 2 yrs of follow-up, smokers who received only negative test results had made fewer quit attempts compared with smokers who received at least one follow-up recommendation $(1.5 \pm 2.0$ versus $1.9 \pm 2.7$ attempts; $\mathrm{p}=0.016)$.

No statistically significant differences were found in smoking abstinence rates between the test negative and test indeterminate group. Point prevalence of smoking abstinence was reported in $54(10.4 \%)$ out of 519 and 51 (12.2\%) out of 419 subjects $(\mathrm{p}=0.39)$, prolonged smoking abstinence in $46(8.9 \%)$ out of 519 and $48(11.5 \%)$ out of 419 subjects $(p=0.19)$, and continued abstinence in $46(8.9 \%)$ out of 519 and $47(11.2 \%)$ out of 419 subjects $(p=0.23)$ in the negative and indeterminate groups, respectively (table 2). Prolonged abstinence rates slightly increased with an increased number of indeterminate test results, from $46(8.9 \%)$ out of 519 subjects after only negative test results to $39(10.9 \%)$ out of 359 subjects after one indeterminate result, and to nine (15\%) out of 60 subjects after two or more indeterminate test results, but this did not reach statistical significance ( $\mathrm{p}=0.26)$ (fig. 2).

Former smokers had quit smoking for $9.0 \pm 10.9$ and $7.6 \pm 11.0$ months in the test negative and indeterminate groups, respectively $(p=0.30)$. The time frame between receiving the last regular test result and the quit date was also comparable for both groups $(7.0 \pm 4.2$ and $6.7 \pm 3.8$ months, respectively; $\mathrm{p}=0.74)$ (table 2$)$.

Furthermore, we found comparable smoking habits among test negatives and test indeterminates who still smoked after 2 yrs of follow-up $(p=0.37)$ (table 2$)$. After multivariate testing, only 


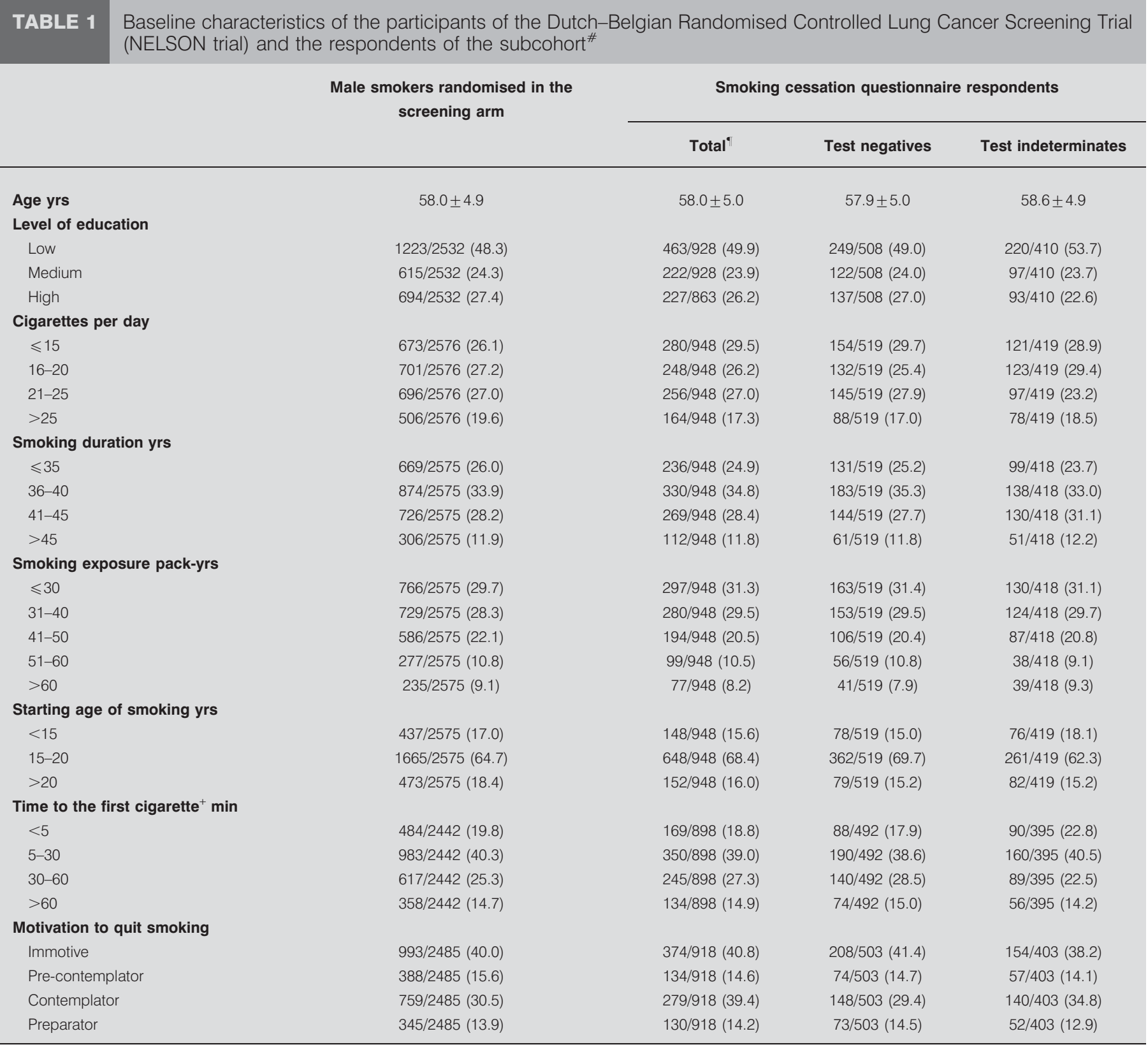

Data are presented as mean \pm SD or $\mathrm{n} / \mathrm{N}(\%)$. Test negatives: male smokers who received only negative test results; test indeterminates: male smokers who received at least one indeterminate test result. Low educational level: primary, lower secondary general or lower vocational education; medium educational level: intermediate vocational education or higher secondary education; high educational level: higher vocational education or university. Immotive: no intention to stop smoking within 1 yr or later; pre-contemplator: intention to stop smoking within 6-12 months; contemplator: intention to stop smoking within 1-6 months; preparator: intention to stop smoking within the next month. ${ }^{*}$ : no selection and/or nonresponse bias was found $(\mathrm{p}>0.05)$; $"$ : data are weighted to correct for the actual distribution of negative and indeterminate screening results in the screening arm; ${ }^{+}$: first question of the Fagerström Test for Nicotine Dependence.

the addiction to nicotine predicted the prolonged abstinence from smoking significantly $(\mathrm{p}=0.006)$ (table 3 ).

\section{DISCUSSION}

The results of our study demonstrated that the lung cancer screening test result (negative or indeterminate) had no statistically significant impact on future smoking abstinence amongst male smokers randomised in the NELSON trial. Nevertheless, all outcome parameters were more favourable for smokers who received at least one indeterminate test result, with a nonsignificant increased quit rate after multiple followup recommendations.

The findings are supported by the studies of ANDERSON et al. [12], Cox et al. [13], OSTROFF et al. [14] and TAYLOR et al. [15], who demonstrated no statistically significant impact of the test result on smoking cessation. The small, but insignificant, increase in the abstinence rates after multiple indeterminate 


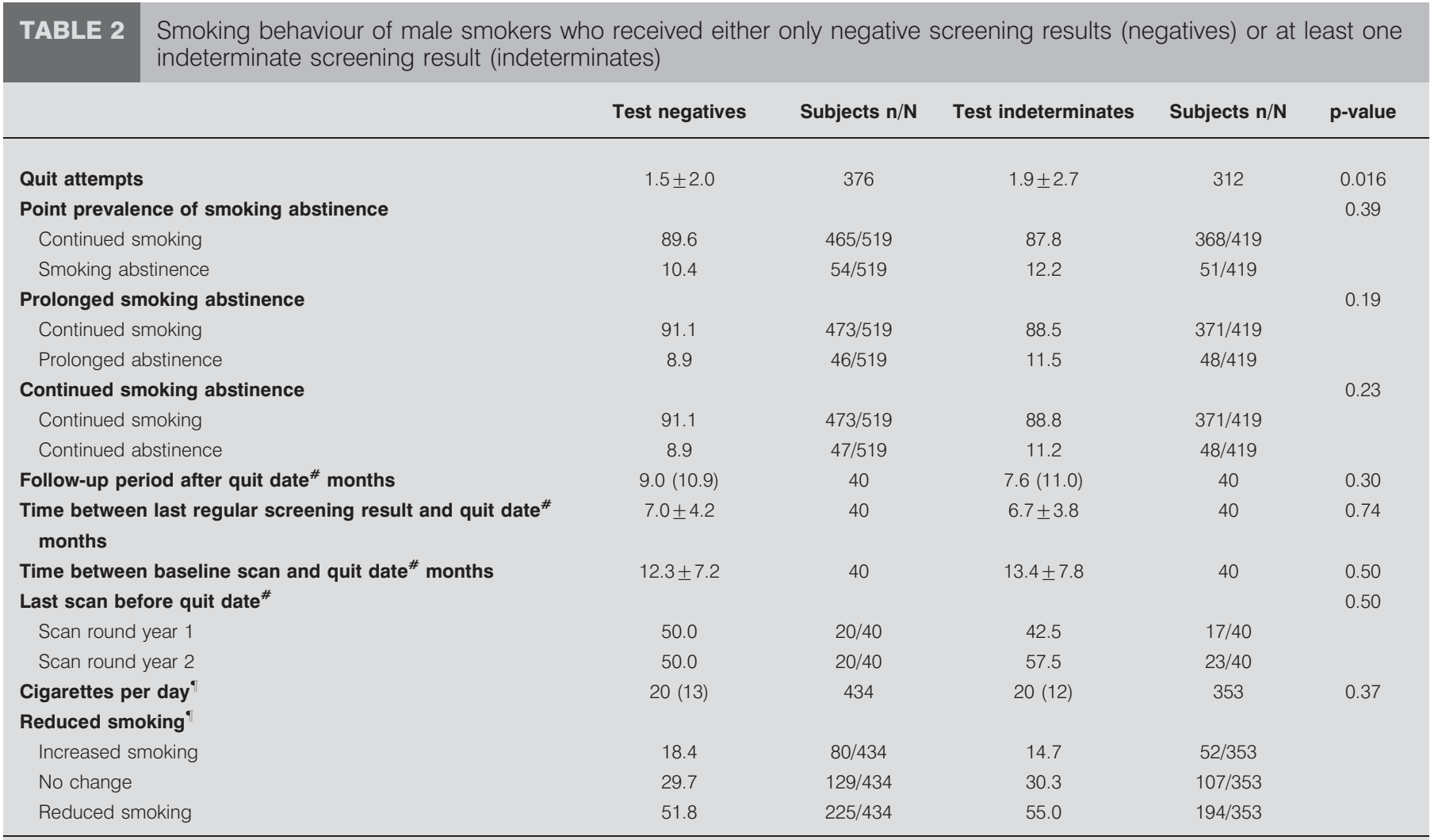

Data are presented as mean \pm SD, \% or median (interquartile range), unless otherwise stated. Test negatives: male smokers who received only negative test results; test indeterminates: male smokers who received at least one indeterminate test result. ${ }^{*}$ : results are based on data for former smokers with complete data of quit date. : results are based on data from respondents who smoked at follow-up.

test results was more or less in line with TownSEND et al. [16], who found a positive association between the number of follow-up recommendations and the smoking abstinence rate. It is expected that this nonsignificant higher quit rate in test indeterminates is a result of the teachable moment of the follow-up procedure. It should be noted that the majority of the

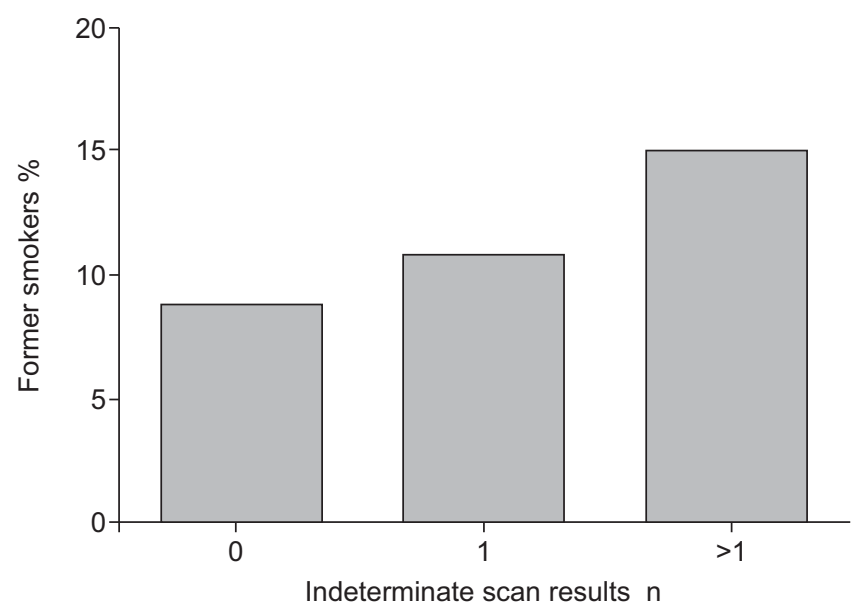

FIGURE 2. Quit rates of male smokers in relation to the number of indeterminate screening result(s) after 2 yrs of follow-up (Chi-squared 2.704, degrees of freedom 2; $n=938 ; p=0.26$ ). smokers who received one or more indeterminate test results also received one or more negative test result during followup, which might underestimate the impact of an indeterminate test result as a teachable moment. That aside, we found that, although the overall quit rate amongst all participants of the NELSON trial was higher than we could expect from the quit rate in the general adult population, the proportion of smoker in the control arm who quit smoking was modest, but statistically significantly $(\mathrm{p}<0.05)$ higher compared with screen arm participants after logistic regression analysis. This raised some concern that lung cancer screening might have a health certificate effect [26]. This means that lung cancer screening might give some participants an unrealistic feeling of reassurance, which leads to continued smoking or even smoking relapse (licence to smoke). From the present study, we cannot conclude whether the outcome of the test is related to smoking relapse. We expected only a limited effect, because ANDERSON et al. [12] reported no increase in smoking relapse after consecutive negative test results compared with referral to the pulmonologist.

A combined approach for both primary and secondary prevention efforts to optimise cancer control is a relatively new research area, and evidence-based guidelines have yet to be published. More research is needed to investigate the opportunities for lung cancer screening in current, as well as former, smokers in order to promote health risk-reducing behaviour change and to prevent relapses [27], and to 
TABLE 3 The univariate and multivariate predictors of prolonged smoking abstinence

\begin{tabular}{|c|c|c|c|c|}
\hline & \multicolumn{2}{|c|}{ Univariate analysis } & \multicolumn{2}{|c|}{ Multivariate analysis } \\
\hline & OR $(95 \% \mathrm{Cl})$ & $\mathrm{p}$-value & OR $(95 \% \mathrm{Cl})$ & p-value \\
\hline \multicolumn{5}{|l|}{ Test result } \\
\hline Only negative & 1.00 & & & \\
\hline$\geqslant 1$ indeterminate & $1.33(0.87-2.04)$ & 0.19 & & \\
\hline Indeterminate & $1.26(0.48-3.30)$ & 0.64 & & \\
\hline Age & $1.02(0.98-1.07)$ & 0.31 & & \\
\hline \multicolumn{5}{|l|}{ Level of education } \\
\hline Low & 1.00 & 0.09 & & \\
\hline Medium & $1.14(0.65-1.98)$ & 0.65 & & \\
\hline High & $1.73(1.06-2.84)$ & 0.029 & & \\
\hline$<15$ & 1.00 & 0.09 & & \\
\hline $15-20$ & $1.70(0.88-3.29)$ & 0.12 & & \\
\hline$>20$ & $0.95(0.40-2.27)$ & 0.91 & & \\
\hline \multicolumn{5}{|c|}{ Time to first cigarette $\min$} \\
\hline$<5$ & 1.00 & 0.005 & 1.00 & 0.006 \\
\hline $5-30$ & $1.99(0.96-4.09)$ & 0.06 & $1.94(0.94-4.00)$ & 0.08 \\
\hline $30-60$ & $1.26(0.56-2.85)$ & 0.58 & $1.28(0.56-2.89)$ & 0.56 \\
\hline$>60$ & $3.42(1.56-7.51)$ & 0.002 & $3.39(1.55-7.45)$ & 0.002 \\
\hline \multicolumn{5}{|c|}{ Motivation to quit smoking } \\
\hline Immotive & 1.00 & 0.55 & & \\
\hline Pre-contemplator & $0.80(0.38-1.66)$ & 0.55 & & \\
\hline Contemplator & $1.25(0.75-2.07)$ & 0.39 & & \\
\hline
\end{tabular}

Low educational level: primary, lower secondary general or lower vocational education; medium educational level: intermediate vocational education or higher secondary education; high educational level: higher vocational education or university. Immotive: no intention to stop smoking within 1 yr or later; pre-contemplator: intention to stop smoking within 6-12 months; contemplator: intention to stop smoking within 1-6 months; preparator: intention to stop smoking within the next month. Bold indicates statistical significance.

investigate what the most cost-effective approach is in this screening population.

When interpreting our results, several limitations of the present study should be considered. First, people with a positive test result were excluded from this sample, because of the low prevalence of positive test results in the screening arm $(2.6 \%)$ as a result of our NELSON nodule management strategy. An indeterminate test result combined with a recommendation for a recall $\mathrm{CT}$ scan as a teachable moment is expected to be less powerful compared with a positive test result, because referral to a pulmonologist for work-up and diagnosis might have more impact on smoking habits compared with receiving our letter with a recommendation for a recall CT scan. This might explain the different outcome of our study compared with the results of STYN et al. [18], who compared those who were referred because of an abnormal CT screening result with those who were test negative.

Another limitation is that our results were restricted to male smokers, because of the low proportion of females in the
NELSON trial (16\%). Although there is no evidence that the impact of participation in a lung cancer screening on smoking behaviour is sex-dependent [13,16-17], our results can only be generalised to male smokers who have undergone CT screening for lung cancer until there is more evidence that CT screening for lung cancer will have no different impact on smoking habits amongst females.

The data were also based on self-completed questionnaires without the biochemical verification of smoking status. This may introduce a social response bias that could affect the impact of CT screening on smoking habits, although it is unlikely that this bias would differ according to screening result. We also assume a limited risk of social response bias since a valid self-reported smoking status was found in a lung cancer screening programme [28]. Therefore, our participants were screened for lung cancer instead of participating in a trial that investigated the impact of a smoking cessation intervention. Nevertheless, we would recommend further investigation of whether self-reported smoking behaviour is valid and reliable amongst participants of a lung cancer screening trial. 
Finally, our results were based on a small sample of current smokers only with the aim of limiting all possible interventions, besides CT screening for lung cancer, in the first year of the trial. The difference in observed smoking abstinence was substantially lower, so that a significant difference could have been missed due to small sample size. Retrospectively, the required sample size for each group to detect the observed quit rates should be 2,500 for a power of $80 \%$.

In conclusion, the outcome of the screening test had no statistically significant impact on future smoking abstinence in male smokers, although all results suggests more favourable implications after one or more follow-up recommendation. Lung cancer screening test outcomes might provide a teachable moment for smoking cessation.

\section{STATEMENT OF INTEREST}

None declared.

\section{ACKNOWLEDGEMENTS}

We would like to thank $C$. van Iersel for the development of the general questionnaire, R. Faber and F. Santegoets (all Erasmus MC, Rotterdam, the Netherlands) for data management, and A.C. de Jongh (Artex B.V., Capelle an der IJssel, the Netherlands) for sending the questionnaires.

\section{REFERENCES}

1 Jemal A, Siegel R, Ward E, et al. Cancer statistics, 2009. CA Cancer I Clin 2009; 59: 225-249.

2 Field JK, Duffy SW. Lung cancer screening: the way forward. $\mathrm{Br} J$ Cancer 2008; 99: 557-562.

3 van Klaveren RJ, Oudkerk M, Prokop M, et al. Management of lung nodules detected by volume CT scanning. N Engl J Med 2009; 361: $2221-2229$.

4 Alberg AJ, Ford JG, Samet JM, et al. Epidemiology of lung cancer: ACCP evidence-based clinical practice guidelines (2nd Edn). Chest 2007; 132: Suppl. 3, 29S-55S.

5 Burns DM. Cigarette smoking among the elderly: disease consequences and the benefits of cessation. Am J Health Promot 2000; 14: 357-361.

6 Taylor DH Jr, Hasselblad V, Henley SJ, et al. Benefits of smoking cessation for longevity. Am J Public Health 2002; 92: 990-996.

7 Emmons KM. A research agenda for tobacco control. Cancer Causes Control 2000; 11: 193-194.

8 Doolan DM, Froelicher ES. Efficacy of smoking cessation intervention among special populations: review of the literature from 2000 to 2005. Nurs Res 2006; 55: Suppl. 4, S29-S37.

9 Copeland AL, Brandon TH. Testing the causal role of expectancies in smoking motivation and behavior. Addict Behav 2000; 25 445-449.

10 Gritz ER, Fingeret MC, Vidrine DJ, et al. Successes and failures of the teachable moment: smoking cessation in cancer patients. Cancer 2006; 106: 17-27.

11 McBride CM, Emmons KM, Lipkus IM. Understanding the potential of teachable moments: the case of smoking cessation. Health Educ Res 2003; 18: 156-170.
12 Anderson CM, Yip R, Henschke CI, et al. Smoking cessation and relapse during a lung cancer screening program. Cancer Epidemiol Biomarkers Prev 2009; 18: 3476-3483.

13 Cox LS, Clark MM, Jett JR, et al. Change in smoking status after spiral chest computed tomography scan screening. Cancer 2003; 98: 2495-2501.

14 Ostroff JS, Buckshee N, Mancuso CA, et al. Smoking cessation following CT screening for early detection of lung cancer. Prev Med 2001; 33: 613-621.

15 Taylor KL, Cox LS, Zincke N, et al. Lung cancer screening as a teachable moment for smoking cessation. Lung Cancer 2007; 56: 125-134.

16 Townsend CO, Clark MM, Jett JR, et al. Relation between smoking cessation and receiving results from three annual spiral chest computed tomography scans for lung carcinoma screening. Cancer 2005; 103: 2154-2162.

17 Ashraf $\mathrm{H}$, Tonnesen $\mathrm{P}$, Pedersen $\mathrm{JH}$, et al. Smoking habits were unaffected by CT screening at 1-year follow-up in the Danish Lung Cancer Screening Trial (DLCST). Thorax 2011; 66: 55-60.

18 Styn MA, Land SR, Perkins KA, et al. Smoking behavior 1 year after computed tomography screening for lung cancer: Effect of physician referral for abnormal CT findings. Cancer Epidemiol Biomarkers Prev 2009; 18: 3484-3489.

19 Van Iersel CA, De Koning HJ, Draisma G, et al. Risk-based selection from the general population in a screening trial: selection criteria, recruitment and power for the Dutch-Belgian randomised lung cancer multi-slice CT screening trial (NELSON). Int J Cancer 2007; 120: 868-874

20 DiClemente CC, Prochaska JO, Fairhurst SK, et al. The process of smoking cessation: an analysis of precontemplation, contemplation, and preparation stages of change. J Consult Clin Psychol 1991; 59: 295-304.

21 Mudde AN, Willemsen MC, Kremers S, et al. Measuring instruments for research regarding smoking and smoking cessation. [Meetinstrumenten voor onderzoek naar roken en stoppen met roken.] The Hague, STIVORO, 2000.

22 Heatherton TF, Kozlowski LT, Frecker RC, et al. The Fagerström Test for Nicotine Dependence: a revision of the Fagerström Tolerance Questionnaire. Br J Addict 1991; 86: 1119-1127.

23 Mudde AN, Willemsen MC, Kremers S, et al. Measuring instruments for research regarding smoking and smoking cessation. [Meetinstrumenten voor onderzoek naar stoppen met roken.] The Hague, STIVORO, 2006.

24 West R, Hajek P, Stead L, et al. Outcome criteria in smoking cessation trials: proposal for a common standard. Addiction 2005; 100: 299-303.

25 Willemsen MC, Wagena EJ, van Schayck CP. [The efficacy of smoking cessation methods available in the Netherlands: a systematic review based on Cochrane data]. Ned Tijdschr Geneeskd 2003; 147: 922-927.

26 van der Aalst CM, van den Bergh KA, Willemson MC, et al. Lung cancer screening and smoking abstinence: 2 year follow-up data from the Dutch-Belgian randomised controlled lung cancer screening trial. Thorax 2010; 65: 600-605.

27 Clark MM, Cox LS, Jett JR, et al. Effectiveness of smoking cessation self-help materials in a lung cancer screening population. Lung Cancer 2004; 44: 13-21.

28 Studts JL, Ghate SR, Gill JL, et al. Validity of self-reported smoking status among participants in a lung cancer screening trial. Cancer Epidemiol Biomarkers Prev 2006; 15: 1825-1828. 